\title{
Robust optmized control of multi levels STATCOM
}

\author{
Tedjini Hamza, Messaoud Fatima Zahra, Kadri Boufeldja \\ SGRE Laboratory Tahri Mohamed University, Algeria
}

\begin{tabular}{l} 
Article Info \\
\hline Article history: \\
Received Sep 11, 2018 \\
Revised May 30, 2019 \\
Accepted Jun 28, 2019 \\
\hline Keywords: \\
Ant colony algorithm (ACA) \\
Lyapunov's theorem \\
Multi levels inverter \\
NPC topology \\
STATCOM
\end{tabular}

\begin{abstract}
Reactive power compensation is an essential part of a power system and the static synchronous compensator (STATCOM) plays an important role in controlling the reactive power flow over the transmission line. The basic building block of the STATCOM is a voltage source inverter (VSI) that generates a synchronous sinusoidal voltage and because of the high MVA ratings, it would be expensive to provide independent, equal, regulated dc voltage sources to power the multilevel converters which are presently proposed for STATCOMs. Dc voltage sources can be derived from the dc link capacitances which are charged by the rectified ac power. In this paper a new stronger control combined of nonlinear control based Lyapunov's theorem and Ant Colony Algorithm (ACA) to maintain stability of multilevel STATCOM and the utility.
\end{abstract}

Copyright $@ 2019$ Institute of Advanced Engineering and Science. All rights reserved.

\section{Corresponding Author:}

TedjiniHamza,

SGRE Laboratory,

Tahrimohamed University,

Bechar, 08000Algeria.

Email: tedjini_h@yahoo.fr

\section{INTRODUCTION}

In 1981, a prototype of an advanced static var compensator, based on force-commutated thyristor technology, was fit reported in the literature [1]. From this prototype, a few units of the STATCOMs based on gate-turn-off thyristors (GTOs), rated around 100 Mvar, have been in service as demonstration models in Japan and in USA [2-3]. Anticipating the days when GTOs can switch at a faster rate, other research groups, mainly from universities, have explored STATCOM concepts based on pulse-width modulation (PWM) techniques [4].Recently, there has been a recognition that the multilevel converter has distinct advantages over the conventional two level converter and several research groups have begin studies to apply it to make the STATCOM more compact and economical [5-6]. To date, the studies have assumed the availability of equal, regulated, dc voltage sources which feed the multilevel converter.

In the control part, the most complete contribution to the stability analysis of nonlinear dynamical systems is due to Lyapunov. Lyapunov's results provide a powerful framework for analyzing the stability of nonlinear dynamical systems. Lyapunov methods have also been used by control system designers to obtain stabilizing feedback controllers fornonlinear systems [7-8]. The ant colony algorithm (ACA), a new analog evolutionary algorithm, is proposed by Marco Dorigo and his co-workers. Since having features of positive feedback, strong robust and parallel processing, the algorithm has solved traveling salesman problem (TSP), quadratic assignment problem (QAP) and job-shop scheduling problem (JSSP) and so on [9-10].

The research of this paper is to improve the stability of STATCOM, when it is under a very complex structure state such as the nine levels NPC topology[11-12], the problem is the nature of this multilevel structure specialy the DC bus which may suffer from the association of many capacitors [13-14]. We propose to usean optimal technic of DC link voltage using ACA applied in the parameter optimization of PI regulator [15], cascaded to a robust control of powers such as the theory of Lyapunov. 


\section{NINE LEVELS VSI BASED STATCOM}

Among the methods used in the control of the STATCOM, the method of instantaneous power control is based on a cascade control based two loops: external in order to stabilize the DC link voltage; this last pilot that controls the inner loop control currents which are images of powers. Schema of nine levels STATCOM with PI control as shown in Figure 1.

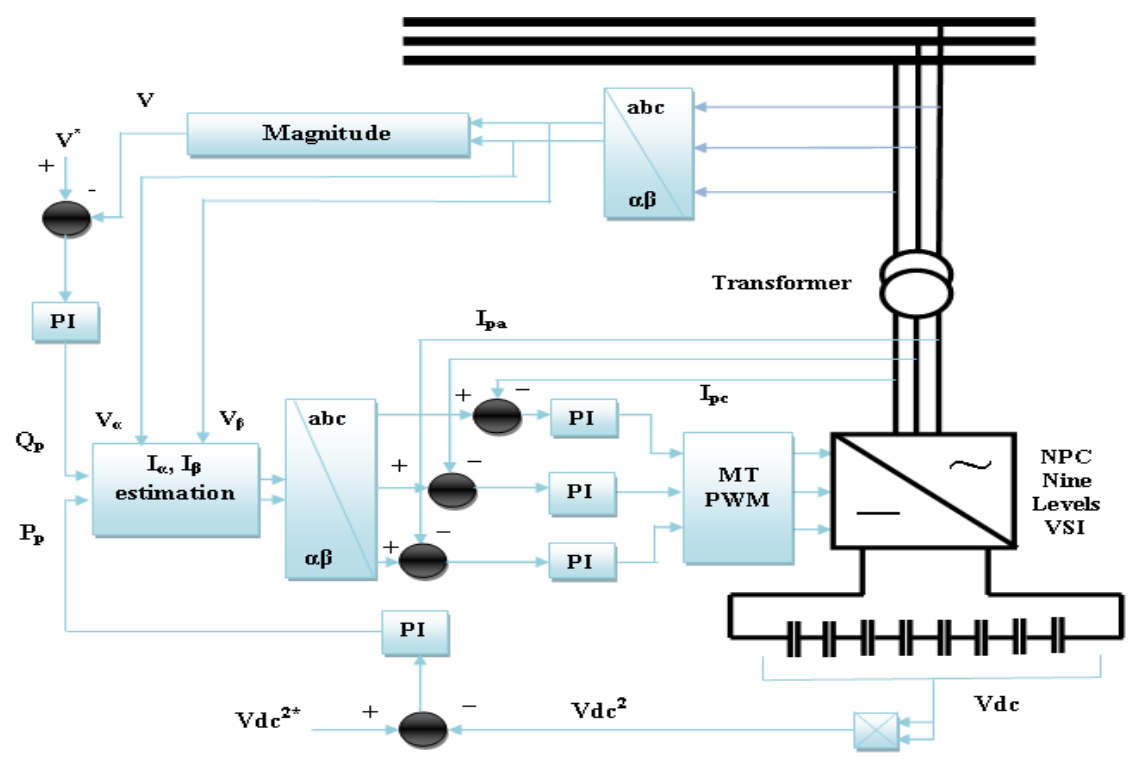

Figure 1. Schema of nine levels STATCOM with PI control

The structure of the neutral point clamped nine levels voltage inverter armconsists of eight secondary sources of DC voltage of value E / 8, twelve IGBT switches and diodes ten looping [16-17].

The function of connecting half - arms defines the relation are as follows:

$$
\begin{aligned}
& k=1,2,3 . \\
& \left\{\begin{array}{c}
F_{k 1}^{b}=F_{k 11} F_{k 12} F_{k 13} F_{k 14} F_{k 15} \\
F_{k 0}^{b}=F_{k 16} F_{k 17} F_{k 18} F_{k 19} F_{k 110}
\end{array}\right.
\end{aligned}
$$

The potentials of nodes A, B and $\mathrm{C}$ of the inverter compared to the midpoint "M" are expressed as shown in (2).

$$
\begin{aligned}
& k=1,2,3=A, B, C \\
& V_{k M}=F_{k 1} F_{k 2}\left(1-F_{k 3}\right) U_{C 1} \\
& +F_{k 1} F_{k 2} F_{k 3}\left(1-F_{k 4}\right)\left(U_{C 1}+U_{C 2}\right) \\
& +F_{k 1} F_{k 2} F_{k 3} F_{k 4}\left(1-F_{k 5}\right)\left(U_{C 1}+U_{C 2}+U_{C 3}\right) \\
& +F_{k 1}^{b}\left(U_{C 1}+U_{C 2}+U_{C 3}+U_{C 4}\right) \\
& -F_{k 6} F_{k 7}\left(1-F_{k 8}\right) U_{C 5} \\
& -F_{k 6} F_{k 7} F_{k 8}\left(1-F_{k 9}\right)\left(U_{C 5}+U_{C 6}\right) \\
& -F_{k 6} F_{k 7} F_{k 8} F_{k 9}\left(1-F_{k 10}\right)\left(U_{C 5}+U_{C 6}+U_{C 7}\right) \\
& -F_{k 0}^{b}\left(U_{C 5}+U_{C 6}+U_{C 7}+U_{C 8}\right)
\end{aligned}
$$

In order to control gates of this converter, we use the Multiple Triangle Modulation (MTPWM) strategy of the seven-level NPC VSI which is formed of eight triangular signals control the pulse of each bridge through two factors: 
a. The factor of regulation $\mathrm{r}=\mathrm{V} * / \mathrm{Vp}$

b. The modulation fraction $\mathrm{m}=\mathrm{fp} / \mathrm{f}^{*}$

\section{MULTIVARIABLE OPTIMAL CONTROL OF MULTI LEVELS STATCOM}

\subsection{Lyapunov's Function Control}

The control of STATCOM is composed of two loops, external loop which has the role of regulation of DC link Voltage and the inner one of the currents control.

Generally nonlinear systems are presented by the state equation:

$$
\dot{x}(t)=f(x, u, t)
$$

The stability studies of each non linear system depend of the identification of the state vector $\mathrm{x}$, which is not determined or fixed [18].

In order to solve this problem, a stability theorem is proposed by Lyapunov that he supposed the existence of a positive scalar function $\gamma(\mathrm{x})$ :

$$
y(x)>0, \forall x \neq 0
$$

Then the proprieties are verified and $(\gamma(0)=0)$ :

The system is stable in order asymptotic if: $\dot{y}(x)=\frac{d y(x)}{d t}<0, \forall x \neq 0$

The system is stable under Lyapunov order or if: $\dot{\gamma}(x)=\frac{d \gamma(x)}{d t} \leq 0, \forall x \neq 0$

The system is stable in order exponential if: $\dot{\gamma}(x)=\frac{d \gamma(x)}{d t} \leq-\beta \cdot \gamma(x), \beta>0 ; \forall x \neq 0$

The studied system is presented in Figure 2.

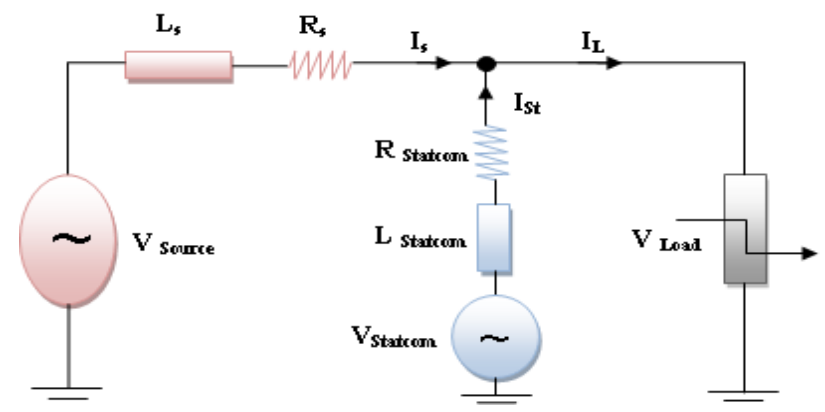

Figure 2. Schema of studied system

The network equations are as follows:

$$
V_{k S}-V_{x S t}=R \cdot i_{k S}+L \cdot \frac{d i_{k s}}{d t}
$$

$\mathrm{k}=1,2,3$ and $\mathrm{x}=\mathrm{a}, \mathrm{b}, \mathrm{c}$ 
$\frac{d i_{k S}}{d t}=\frac{1}{L}\left[\left(V_{k S}-V_{x S t}\right)-R . i_{k S}\right]$

The Lyapunov function is fixed as:

$$
\begin{aligned}
& \gamma_{k}\left(e_{k}\right)=\frac{1}{2} e_{k}^{2} \\
& e_{k}=\left(i_{k r e f}-i_{k S}\right) \\
& \dot{\gamma}_{k}\left(e_{k}\right)=e_{k} \cdot \dot{e}_{k}=\left(i_{k r e f}-i_{k S}\right) \cdot\left(\frac{d i_{k r e f}}{d t}-\frac{d i_{k S}}{d t}\right) \\
& \dot{\gamma}_{k}\left(e_{k}\right)=e_{k}\left[\frac{d i_{k r e f}}{d t}-\left(\frac{V_{k S}-V_{x S t}-R \cdot i_{k S}}{L}\right)\right]
\end{aligned}
$$

In order to obtain a negative derived of function of Lyapunov, we take:

$$
V_{S t}=\left[V_{k S}-R \cdot i_{k S}-B_{k} \cdot L \cdot\left(i_{k r e f}-i_{k S}\right)-\frac{L d i_{k r e f}}{d t}\right]
$$

Then:

$$
\dot{\gamma}_{k}\left(e_{k}\right)=-B k \cdot\left(i_{k r e f}-i_{k S}\right)^{2}=-B_{k} \cdot e_{k}^{2}<0
$$

\subsection{Ant's Colony Optimization ACO}

The main idea of Ant's Colony Algorithm is to model the problem as the search for a minimum cost path in a graph that base the evolutionary meta-heuristic algorithm. The behavior of artificial ants is inspired from real ants. They lay pheromone trails and choose their path using transition probability. Ants prefer to move to nodes which are connected by short edges with a high among of pheromone. The algorithm has solved traveling salesman problem (TSP), quadratic assignment problem (QAP) and job-shop scheduling problem (JSSP) and so on.

The problem must be mapped into a weighted graph, so the ants can cover the problem to find a solution. The ants are driven by a probability rule to choose their solution to the problem (called a tour). The probability rule (called Pseudo-Random-Proportional Action Choice Rule) between two nodes i and j [9].

$$
P_{i j}^{k}(t)=\frac{\left(\tau_{i j}(t)\right)^{\alpha} \cdot\left(\eta_{i j}\right)^{\beta}}{\sum_{l \in N}\left(\tau_{i l}(t)\right)^{\alpha} \cdot\left(\eta_{i l}\right)^{\beta}}
$$

The heuristic factor ij or visibility is related to the specific problem as the inverse of the cost function. This factor does not change during algorithm execution; instead the metaheuristic factor $\zeta \mathrm{ij}$ (related to pheromone which has an initial value $\zeta 0$ ) is updated after iteration.

The parameters $\alpha$ and $\beta$ enable the user to direct the algorithm search in favor of the heuristic or the pheromone factor. These two factors are dedicated to every edge between two nodes and weight the solution graph.

The pheromones are updated after a tour is built, in two ways: firstly, the pheromones are subject to an evaporation factor $\rho$, which allows the ants to forget their past and avoid being trapped in a local minimum. Secondly, they are updated in relation to the quality of their tour, where the quality is linked to the cost function.

$$
\tau_{i j} \rightarrow(1-\rho) \cdot \tau_{i j}, \forall(i, j) \in L
$$




$$
\begin{aligned}
& \tau_{i j} \rightarrow \tau_{0}+\sum_{k=1}^{m} \Delta \tau_{i j} ; \forall(i, j) \in L \\
& \Delta \tau_{i j}=\frac{1}{C^{k}}
\end{aligned}
$$

Where $\mathrm{m}$ is the number of ants, $\mathrm{L}$ represents the edges of the solution graph, and $\mathrm{Ck}$ is the cost function of tour Tk, built by the kth ant.

\subsection{ACO PI for Voltage DC Link Balancing Control}

For a given plant, the problem of designing a PI controller is to adjust the parameters $\mathrm{Kp}$ and $\mathrm{Ki}$ for getting a desired performance of the considered system. Both the amplitude and time duration of the transient response must be kept within tolerable or prescribed limits, for this condition, three key indexes performance of the transient response are utilized to characterize the performance of PI control system. These key indexes maximum overshoot, rise time and integral absolute control error are adopted to create objective function which is defined as:

$$
F=f_{o s}+f_{r t}+f_{\text {ias }}
$$

The maximum overshoot is defined as:

$$
f_{o s}=y_{\max }-y_{s s}
$$

Where $y_{\max }$ characterize the maximum value of y and $y_{s s}$ denote the steady-state value of y. For represent the function of the rise time is defined as the time required for the step response. Schema of nine levels STATCOM with PI control as shown in Figure 3. In the other hand, the integral of the absolute magnitude of control error is written as:

$$
f_{\text {ias }}=\int_{0}^{\infty}|e(t)| d t
$$

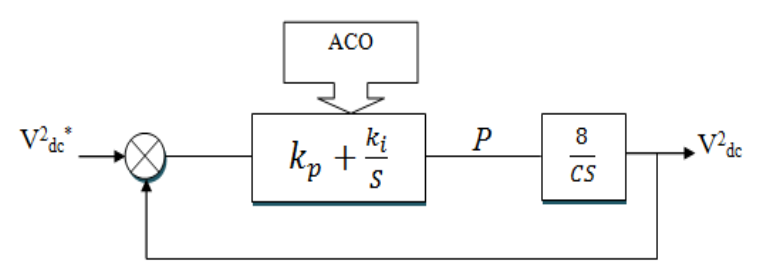

Figure 3. Schema of nine levels STATCOM with PI control

Each parameter of $\mathrm{Kp}$ and $\mathrm{Ki}$ is hinted by 100 nodes respectively and there is resolution 0.0001 among each node, one node represents a solution value of parameters $\mathrm{Kp}$ and $\mathrm{Ki}$ [10, 19-21].

\section{RESULTS AND ANALYSIS}

Under same cases in per unit; we will examine the response of STATCOM and its performances using two controls types, firstly we use the classical PI control and secondly we observe the impact when we use the optimized control.

The power network $($ Vbase $=10 \mathrm{kV}$, Ibase $=110 \mathrm{~A})$ is connected to a three phases line $(\mathrm{r}=4.8 \Omega$, $\mathrm{L}=0.1552 \mathrm{H}$ ) feeding three phases load. As an instability case, a 1320KVAR inductive overload is applied between $\mathrm{t} 1=0.3 \mathrm{~s}$ and $\mathrm{t} 2=1 \mathrm{~s}$. The studies are carried out using MATLAB; the studied system is represented in Figure 4. 


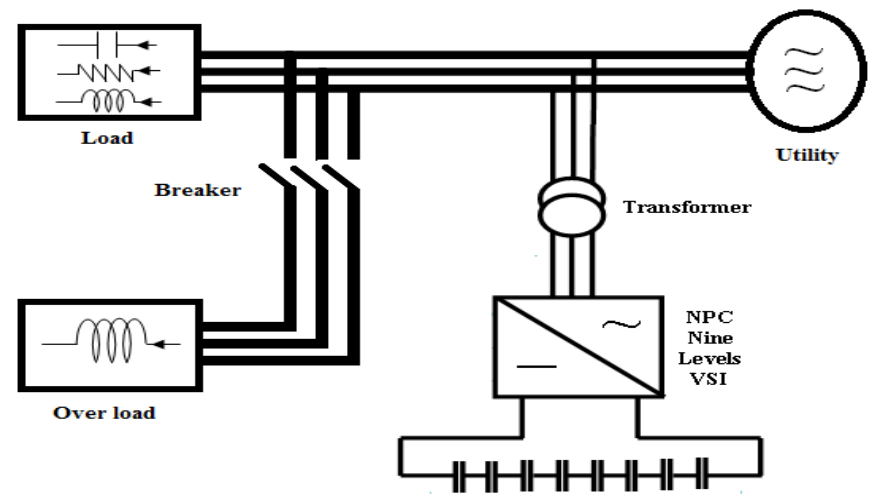

Figure 4. General representation of studied system

\subsection{PI Control}

\subsubsection{Load Side}

Since the breaker opening, the reactive power is growth about 0.3pu as shown in Figure 5.

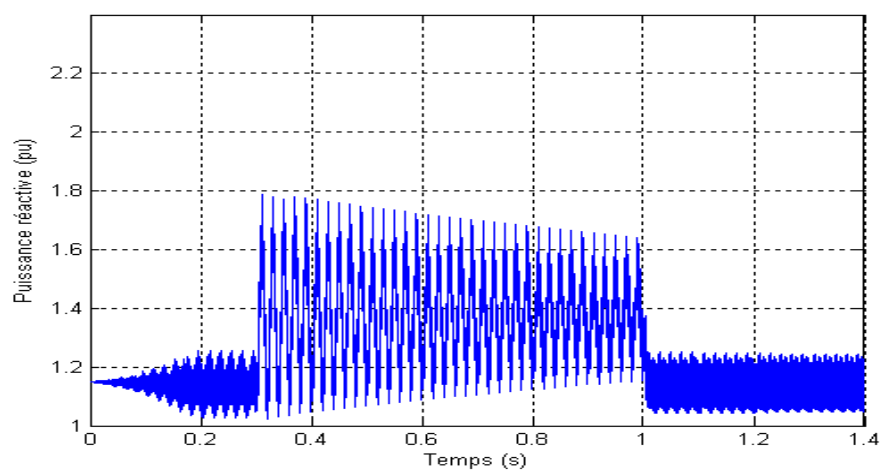

Figure 5. Reactive power of load

\subsubsection{STATCOM}

MTPWM control, STATCOM voltage, Control of current (Phase A) and Voltage magnitude control as shown in Figure 6-9. Figure 10 shows that the STATCOM try to absorb the variation and the growth of reactive power; we can observe $40 \%$ of overshoots and a large response time,especially in the case of the global DC link voltage. DC link voltage control as shown in Figure 11.

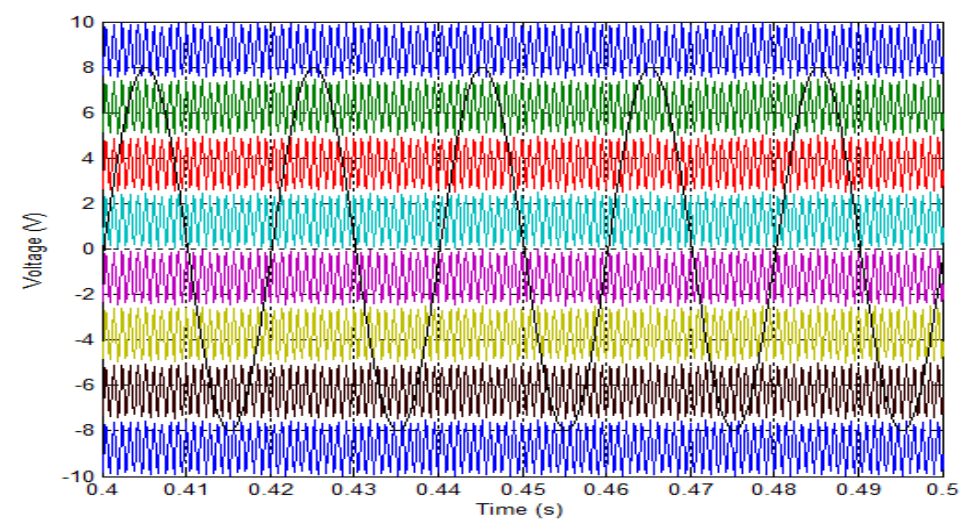

Figure 6. MTPWM control 


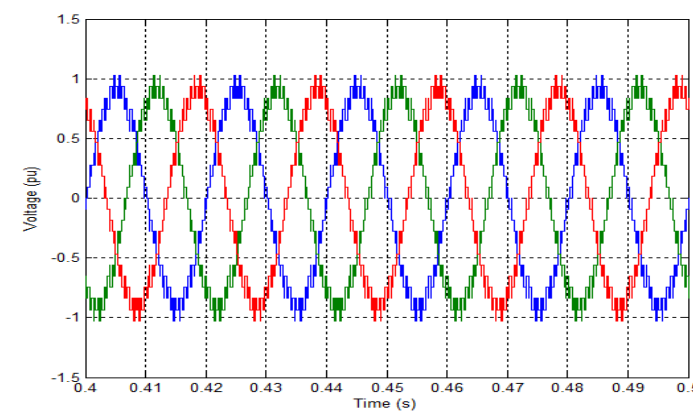

Figure 7. STATCOM voltage

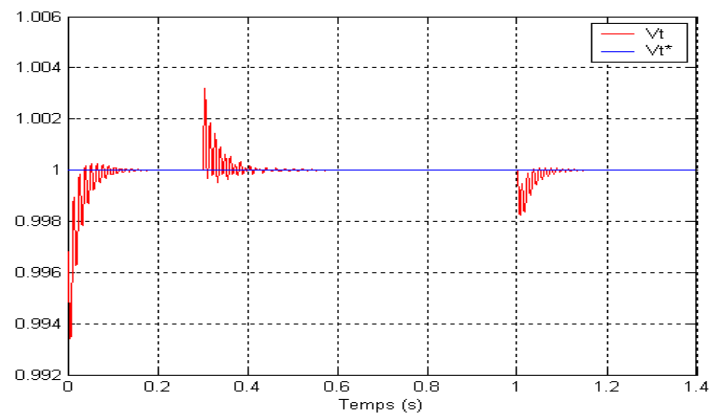

Figure 9. Voltage magnitude control

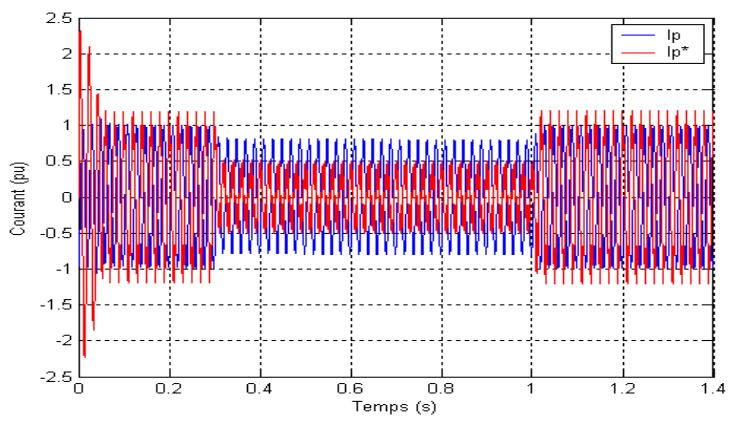

Figure 8. Control of current (Phase A)

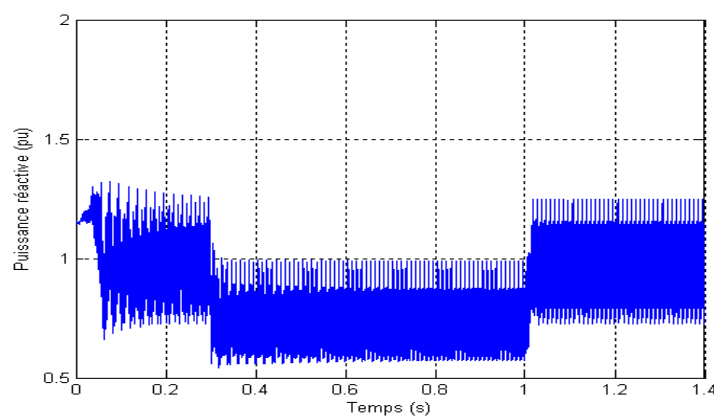

Figure 10. Reactive power of STATCOM

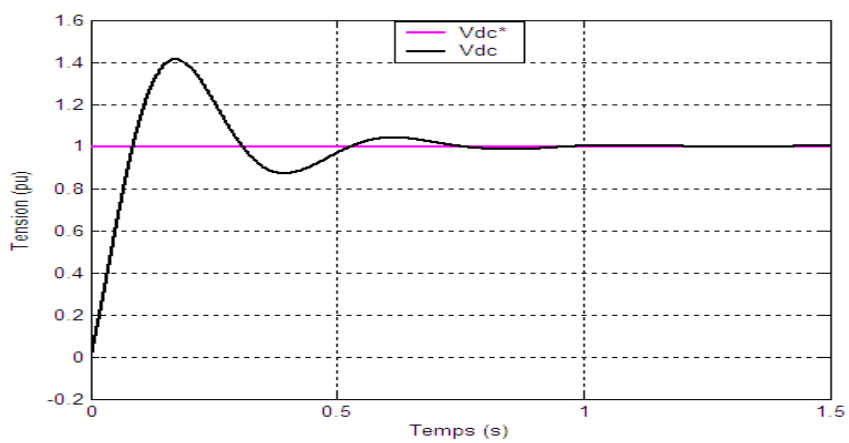

Figure 11. DC link voltage control

\subsubsection{Source Side}

TheStatcom cannot stop the instability perfectly of the reactive energy to arrive in the network part as shown in Figure 12.

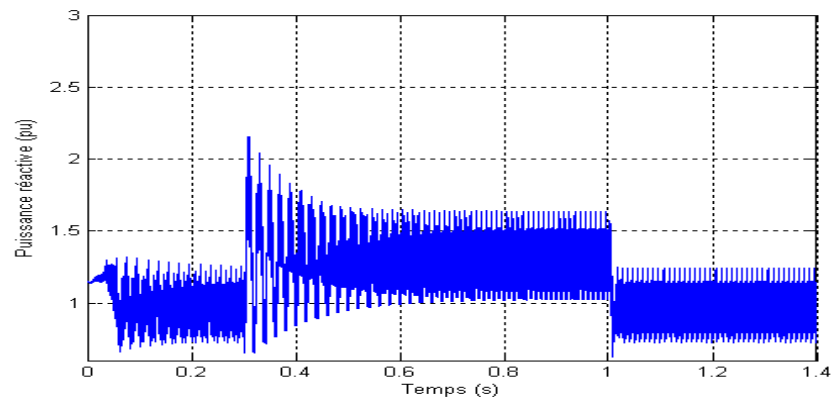

Figure 12. Reactive power in source side 


\subsection{CO-Lyapunov Control}

\subsubsection{Load Side}

Figure 13 shows an increase of reactive power almost $1.42 \mathrm{pu}$. Which is imposed by a current rise; the voltage of the region does not change.

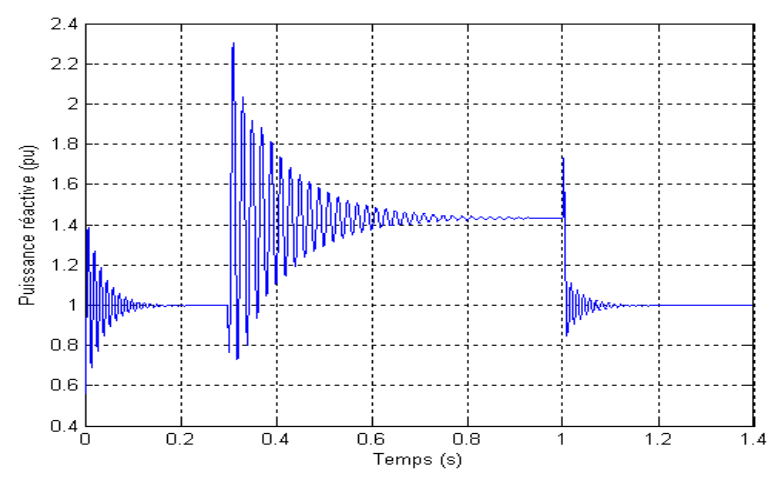

Figure 13. Reactive power of load

\subsubsection{STATCOM} in Figure 14.

The multilevel voltage of Statcom is presented in Figure 15 and MTPWM control as shown

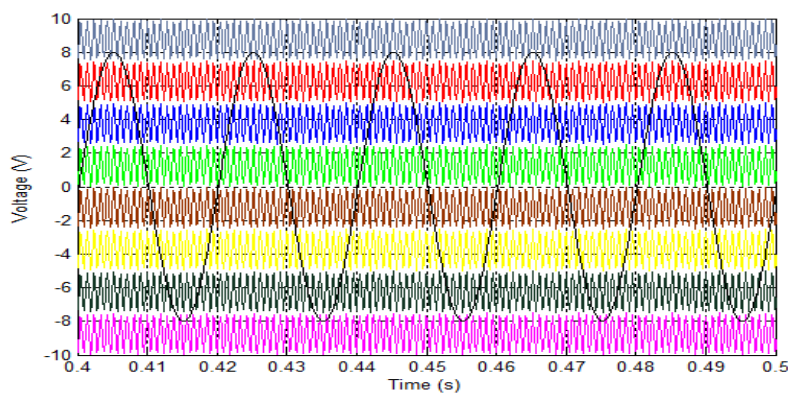

Figure 14. MTPWM control

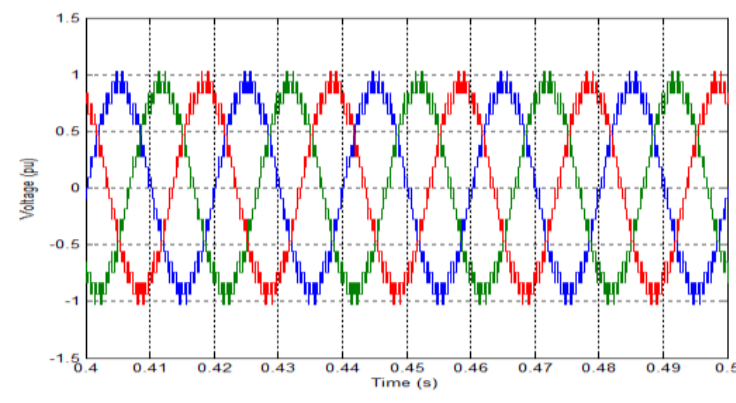

Figure 15. STATCOM voltage

After running, we have the following values: $\mathrm{Ki}=0.1457, \mathrm{Kp}=1.5708$.

The introduction of the ACO optimization allowing for removal of the excess with a very short response time, it can be seen on Figure 17 compared with Figure 11. Optimization of objective function as shown in Figure 16.

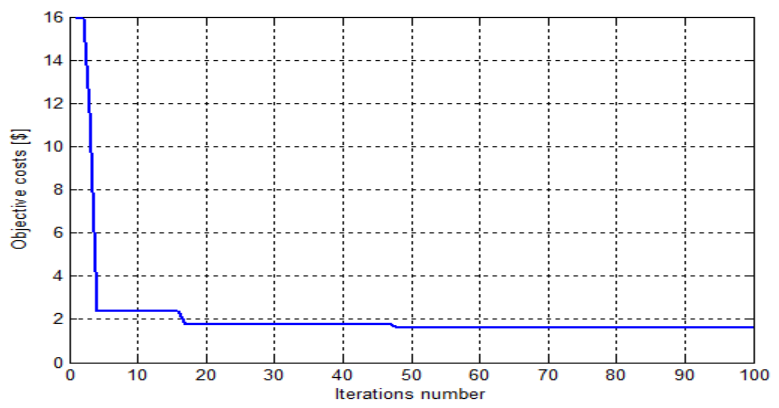

Figure 16. Optimization of objective function

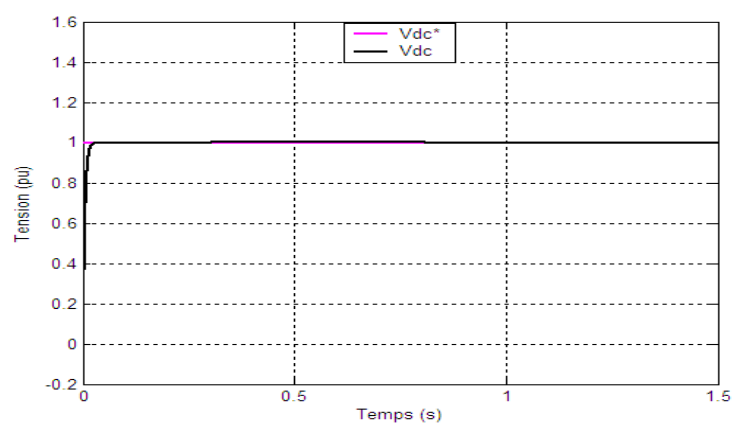

Figure 17. DC link voltage control 
Figures18 and 19 shows that the STATCOM absorb reactive power during the fault to stabilize reactive energy. Hence we see that the reactive power and currentwere impoverished during this period. Voltage magnitude control as shown in Figure 20.

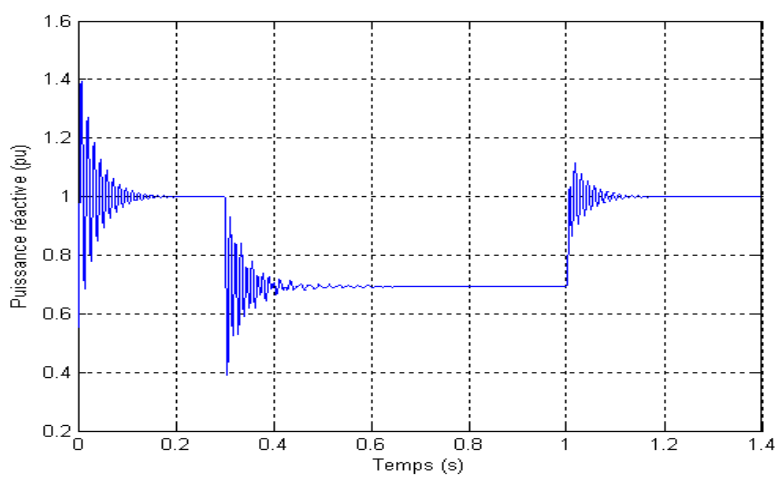

Figure 18. Reactive power of STATCOM

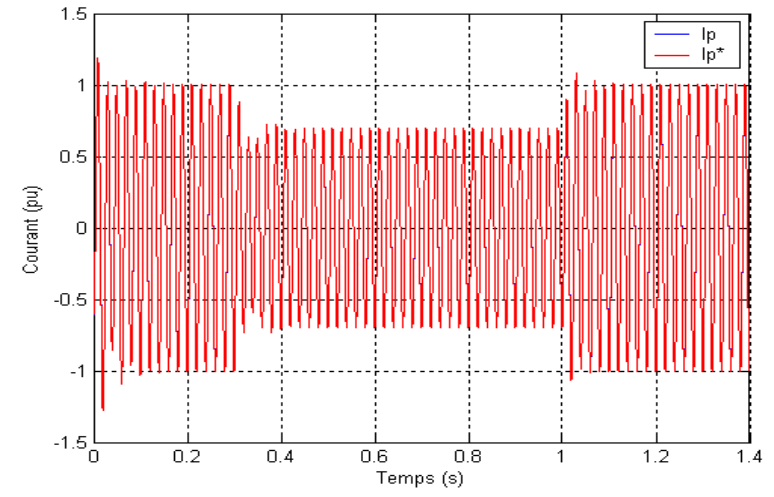

Figure 19. Control of current (Phase A)

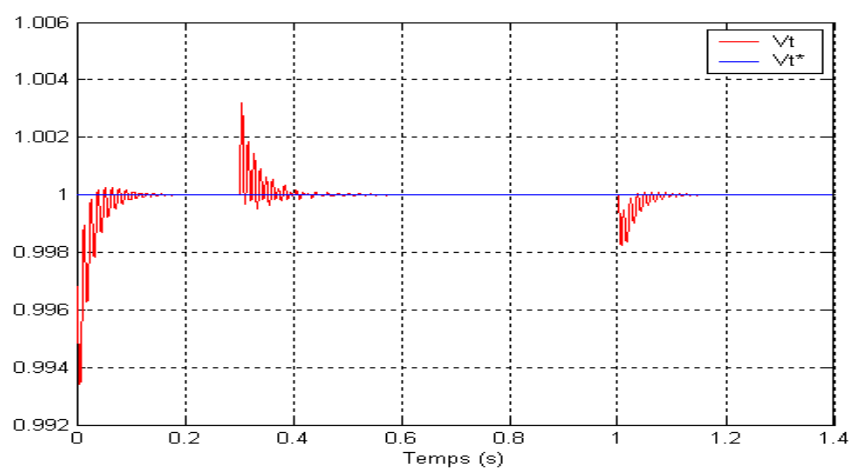

Figure 20. Voltage magnitude control

\subsubsection{Source Side}

As noted in Figure 21 that the reactive power is oriented towards stability without any increase because of the robustness of the nonlinear control. So we can conclude that the STATCOM to absorb all the default and keep the stability of the network.

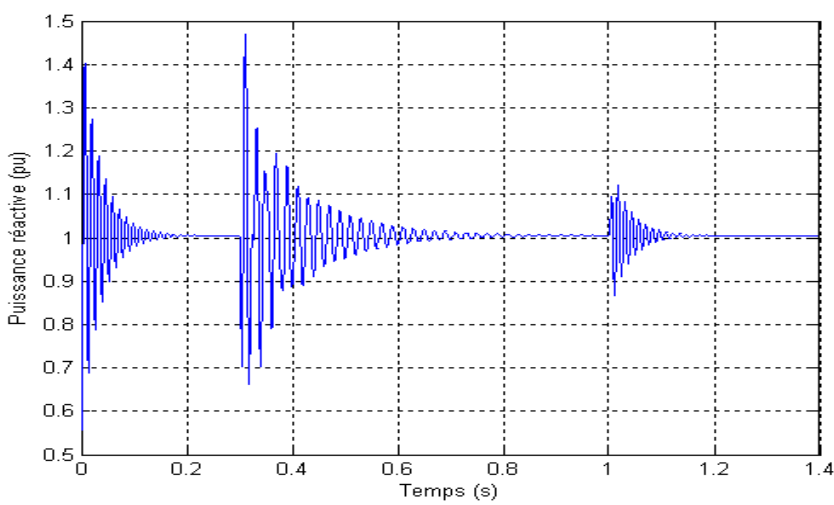

Figure 21. Reactive power in source side 


\section{CONCLUSION}

We brought this study on the STATCOM which has several advantages: a) Good damping of power swings. b) Support voltage in disturbed operating. c) Help the early return to stability. The multi-level structure appears as a solution to the limitation of the voltage of IGBT components as well the economic side particularly with regard to the transformer. The results obtained using the command of ACO-Lyapunov indicates better performances compared to those obtained by conventional control.

\section{REFERENCES}

[1] N. G. Hingorani, "Flexible ac transmission," IEEE Spectrum, April 1993, pp. 40-45,

[2] L. Gyugyi, "A unified power flow control concept for flexible ac transmission systems," IEEE proceedings-C, Vol. 139, July 1992, pp. 323-331.

[3] M.I Mossad, "Model reference adaptive control of STATCOM for grid integration of wind energy systems", IET Electric Power Applications, Vol. 12, N 5, pp. 605-613, 2018.

[4] R. Mechouma, H. Aboub, B. Azoui, "Multicarrier wave dual reference very low frequency PWM control of anine levels NPC multi-string three phase inverter topology for photovoltaic system connected to a medium electric grid", 49th International Universities Power Engineering Conference (UPEC), pp. 1-6, 2014.

[5] F. Bouchafaa; E. M. Berkouk; M. S. Boucherit, "Analysis and simulation of a multilevel inverter converter NPC Cascade", International Conference on Computer Engineering \& Systems, pp. 285-290.

[6] K. Anuradha; Gandla Radha Krishna, "Neutral point voltage level stabilization and DC link capacitors voltage balance in neutral point clamped multilevel inverters", 11th International Conference on Industrial and Information Systems (ICIIS), pp. 838-843, 2016.

[7] S. G. Nersesov, W. M. Haddad, "On the Stability and Control of Nonlinear Dynamical Systems via Vector Lyapunov Functions" IEEE trans., Vol. 51, Feb. 2006, pp. 203-215.

[8] J. Y. Ishihara, M. H. Terra, "On the Lyapunov Theorem for Singular Systems" IEEE trans. on Automatic Control, Vol. 47, Nov.2002, pp. 1926-1930.

[9] M. Dorigo, L M. Gambardella, "Ant Colony System: A Cooperation Learning Approach to the Traveling Salesman Problem", IEEE Trans, Vol. 1, no. 1, pp. 53-66, 1997.

[10] Ashraf M. Abdelbar, Stubborn Ants, IEEE Swarm Intelligence Symposium, St. Louis MO USA, September 21-23, 2008.

[11] Dong Chen; Lie Xu; Yan Xu, “ DC STATCOM in multi-terminal DC distribution power system”, The Journal of Engineering, Vol. 2017, N 13, pp. 2077-2082, 2017.

[12] N. Cherkaoui, T. Haidi, A. Belfqih, F. El Mariami, J. Boukherouaa, "A Comparison Study of Reactive Power Control Strategies in Wind Farms with SVC and STATCOM," International Journal of Electrical and Computer Engineering (IJECE), Vol. 8, No. 6, December 2018, pp. 4836-4846.

[13] G.M. Reddy, T.G. Manohar, "Multi Level Inverter Based STATCOM for GridConnected Wind Energy Conversion System", International Journal Of Renewable Energy Research, Vol.7, No.1, 2017.

[14] OJK. Oghorada, L. Zhang, L (2018) "Analysis of star and delta connected modular multilevel cascaded converterbased STATCOM for load unbalanced compensation.” International Journal of Electrical Power and Energy Systems (IJPEDS), 95. pp. 341-352. ISSN 0142-0615.

[15] B. Berbaoui, C. Benachaiba, M. Rahli, H. Tedjini, , "An efficient algorithm to tuning PI-controller parameters for shunt active power filter using ant colony optimization " Przegląd Elektrotechniczny, ISSN 0033-2097, June 2011, pp. 140-145.

[16] L. Li, D. Czarkowski, L. Yaguang, and P. Pillay, "Multilevel spacevector PWM technique based on phase-shift harmonic suppression", Proc. 15th Applied Power Electronics Conf. (APEC), 2000, Vol. 1, pp. 535-541.

[17] A. Ramesh1, O. Chandra Sekhar, M. Siva Kumar, "A Novel Three Phase Multilevel Inverter with Single DC Link for Induction Motor Drive Applications”, International Journal of Electrical and Computer Engineering (IJECE), Vol. 8, No. 2, April 2018, pp. 763-770.

[18] M. N. Kamarudin, S. M. Rozali, T. Sikno, A. R. Husain,” New robust bounded control for uncertain nonlinear systemusing mixed backstepping and lyapunov redesign", International Journal of Electrical and Computer Engineering (IJECE), Vol. 9, No. 2, April 2019, pp. 1090-1099.

[19] I. Tahyudin, Hidetaka Nambo, "Improved optimization of numerical association rule mining using hybrid particle swarm optimization and cauchy distribution”, International Journal of Electrical and Computer Engineering (IJECE), Vol. 9, No. 2, April 2019, pp. 1359-1373.

[20] A. M. Hasan, "A Hybrid Approach of Using Particle Swarm Optimization andVolumetric Active Contour without Edge for Segmenting BrainTumors in MRI Scan”, IJEEI, Vol. 6, No. 3, September 2018, pp. 292-300.

[21] K. Lenin, B.R. Reddy, “ Reduction of Active Power Loss byUsing Adaptive Cat Swarm Optimization”, IJEEI, Vol. 2, No. 3, September 2014, pp. 111-118. 